\title{
Transcriptional Remodeling of Ion Channel Subunits by Flow Adaptation in Human Coronary Artery Endothelial Cells
}

\author{
Eirini Kefaloyianni $^{\mathrm{a}} \quad$ William A. Coetzee $^{\mathrm{a}-\mathrm{c}}$ \\ Departments of a Pediatrics, b Pharmacology, and 'Physiology and Neuroscience, New York University School of \\ Medicine, New York, N.Y., USA
}

Key Words

Coronary artery $\cdot$ Endothelium $\cdot$ Ion channel $\cdot$ Shear

\begin{abstract}
Endothelial cells (ECs) are constantly exposed to blood flowinduced shear forces in the vessels and this is a major determinant of endothelial function. Ion channels have a major role in endothelial function and in the control of vascular tone. We hypothesized that shear force is a general regulator of ion channel expression, which will have profound effects on endothelial function. We examined this hypothesis using large-scale quantitative real-time RT-PCR. Human coronary artery ECs were exposed to two levels of flow-induced shear stress for $24 \mathrm{~h}$, while control cells were grown under static conditions. The expression of ion channel subunits was compared between control and flow-adapted cells. We used primers against 55 ion channel and exchanger subunits and were able to detect 54 subunits. Five dyn $/ \mathrm{cm}^{2}$ of shear induced downregulation of 1 (NCX1) and upregulation of 18 subunits, including $\mathrm{K}_{\mathrm{Ca}} 2.2, \mathrm{~K}_{\mathrm{Ca}} 2.3, \mathrm{CX} 37, \mathrm{~K}_{\mathrm{v}} 1.5$ and HCN2. Fifteen dyn $/ \mathrm{cm}^{2}$ of shear stress induced the expression of 30 ion channel subunits, including $\mathrm{K}_{\mathrm{Ca}_{\mathrm{a}}} 2.3, \mathrm{~K}_{\mathrm{Ca}} 2.2, \mathrm{CX} 37, \mathrm{~K}_{\mathrm{ir}} 2.3$ and $\mathrm{K}_{\mathrm{Ca}}$ 3.1. Our data demonstrate that substantial remodeling of endothelial ion channel subunit expression occurs
\end{abstract}

with flow adaptation and suggest that altered ion channel expression may significantly contribute to vascular pathology associated with flow-induced alterations.

Copyright $\odot 2011$ S. Karger AG, Basel

\section{Introduction}

Endothelial cells (ECs) line in the luminal side of blood vessels and are constantly exposed to shear stress due to fluctuations in blood flow. Changes in these shear forces are sensed by the endothelium and are responsible for mechanochemical signal transduction [1]. It is well documented that flow-sensitive ion channels, integrins, receptor tyrosine kinases, $G$ protein-coupled receptors, lipid domains of the membrane and the cytoskeleton are all involved in sensing of shear $[2,3]$. This results in activation of intracellular signaling pathways and subsequent changes in structural elements as well as alterations in gene expression patterns of the EC. Cumulatively, these responses lead to major changes in endothelial functions, including proliferation, apoptosis, alignment, migration and permeability $[3,4]$. The ability of ECs to sense flow allows acute flow-mediated arterial vasoconstriction and vasodilation as well as wall remodeling due to chronic

\section{KARGER}

(C) 2011 S. Karger AG, Basel

Fax +41613061234 E-Mail karger@karger.ch www.karger.com www.karger.com/jvr
Dr. William A. Coetzee

Pediatric Cardiology, New York University School of Medicine

560 First Avenue, TCH-521

New York, NY 10016 (USA)

Tel. +1 212263 8518, E-Mail william.coetzee@med.nyu.edu 
changes in flow [5]. Moreover, abnormalities in flow-mediated responses of ECs, for example during endothelial dysfunction, are associated with vascular pathology. Accumulating data suggest that disturbed or oscillatory flow is proatherogenic, through the induction of proinflammatory, procoagulant, proliferative and proapoptotic molecules, and sustained laminar flow provides protection from atherosclerosis through the induction of antithrombotic and antiproliferative factors $[3,5,6]$.

Among the first cellular components identified to mediate the endothelial response to shear were ion channels. In particular, it was shown that shear stress induces rapid activation of inward-rectifying $\mathrm{K}^{+}$currents that result in membrane hyperpolarization and $\mathrm{Ca}^{2+}$ entry. Subsequently, various types of $\mathrm{Ca}^{2+}$-permeable cation channels, $\mathrm{K}^{+}$channels, and $\mathrm{Cl}^{-}$channels have also been implicated in endothelial mechanosensing [7-11]. The longterm effects that flow has on ion channel expression and function are poorly investigated. It has been reported that flow mediates changes in the expression of specific ion channel subunits in the endothelium. For example, the intermediate-conductance $\mathrm{Ca}^{2+}$ channel subunit $\mathrm{K}_{\mathrm{Ca}} 3.1$ [12], ATP-sensitive $\mathrm{K}^{+}\left(\mathrm{K}_{\mathrm{ATP}}\right)$ channel subunit $\mathrm{K}_{\mathrm{ir}} 6.2$ [13] and the T-type voltage-gated $\mathrm{Ca}^{2+}$ channel subunit $\mathrm{Ca}_{\mathrm{v}} 3.1$ [14] are reported to be upregulated by flow. Based on these findings, we hypothesized that shear force is a general regulator of ion channel expression, which will have profound effects on endothelial function. In order to test our hypothesis, we used a large-scale quantitative RTPCR assay (qRT-PCR) to examine the transcriptional levels of about 60 ion channel and exchanger subunits in ECs that have been cultured under static or flow-adapted conditions. We found that a remarkable transcriptional upregulation of ion channels occurs with flow adaptation that is also dependent on the levels of flow.

\section{Materials and Methods}

\section{Flow Adaptation of ECs}

Human coronary artery ECs (HCAECs; Lonza, Walkersville, Md., USA) were grown in EGM2-MV (Lonza) and were used between the 4 th and 6 th passage. HCAECs were exposed to defined amounts of shear stress using an artificial capillary system (FiberCell $\left.^{\mathrm{TM}} 4300-\mathrm{C} 2025\right)$ as previously described [15]. Artificial capillaries were activated according to the manufacturer's instructions and precoated with $0.2 \%$ gelatin. Cells were allowed to attach for $18 \mathrm{~h}$ and constant laminar flow sufficient to generate 5 or 15 dyn/ $\mathrm{cm}^{2}$ of shear force was applied for $24 \mathrm{~h}$. The two levels of shear stress were selected based on a large body of previously published data. Control cells (same passage and confluence) were grown in plates under static culturing conditions.
Large-Scale qRT-PCR

We used qRT-PCR to quantify the mRNA expression of a large number of ion channel transcripts, as described previously [16]. We used primers against 56 ion channel and exchanger subunits, designed with the Primer3 software [17]. The selection was made based on expression profiling data obtained from microarray data with ECs and other literature sources. Primers were designed to span two exons to avoid PCR amplification of genomic sequences. Other design considerations included a melting temperature of $60^{\circ} \mathrm{C}$ and a PCR amplicon of $90-120$ base pairs. Total RNA was extracted from control and flow-adapted cells by the acid phenol guanidinium method (TriReagent, Sigma-Aldrich, St. Louis, Mo., USA). Total RNA was reverse transcribed using the Superscript III enzyme (Invitrogen) with random hexamer primers according to the manufacturer's guidelines. PCRs were performed with an ABI Prism 7900HT sequence detection system (Perkin-Elmer Applied Biosystems) with a SYBR green master mix (Perkin-Elmer Applied Biosystems). The thermal cycling conditions comprised an initial denaturing step at $95^{\circ} \mathrm{C}$ for $10 \mathrm{~min}$ and 40 cycles at $95^{\circ} \mathrm{C}$ for $5 \mathrm{~s}, 60^{\circ} \mathrm{C}$ for $15 \mathrm{~s}$, and $72^{\circ} \mathrm{C}$ for $15 \mathrm{~s}$, followed by a melting curve analysis.

\section{Data Analysis}

The PCR threshold cycle (the fractional cycle number at which the fluorescence level is distinguishable from the background, $\mathrm{Ct}$ ) values were measured within the exponential phase of the PCR using SDS software (version 2.2, Applied Biosystems). Reactions with any evidence of nonspecificity (low melting temperatures or multiple peaks in melting-point analysis) were excluded from the analysis. We performed an initial characterization of the qRTPCR assay in terms of its reproducibility and sensitivity. There was a high degree of reproducibility within plates [16]. The median value of the coefficient of variation of Ct values for triplicate reactions for the data presented in this study was 1.58\% (range: $0.01-18.68 \%)$.

It is increasingly common with qRT-PCR to use a set of reference genes to estimate gene expression levels (e.g. $[16,18])$. We have used this technique in the present study and calculated expression values of each gene relative to the geometric mean of the three reference genes ('housekeeping' genes). For a given experiment, the expression of each gene was measured in triplicate (technical replicates), which was averaged to obtain a single expression value for that gene. The values plotted in figure 1 represent the average from 6 independent experiments (biological replicates). The subset of reference genes used included histone $\mathrm{H} 3$, hydroxymethylbilane synthase and dihydrofolate reductase, as previously described [16]. The selection of stable reference genes (i.e. that did not change their expression with flow adaptation) was made using the Normfinder algorithm [19]. The relative expression of ion channel subunits calculated for the flow-adapted cells was compared with the relative expression of the subunits calculated for the control cells (cultured under static conditions) to obtain the fold induction or suppression of the subunit expression. Statistical analysis was performed using a nonparametric test, the Significance Analysis of Microarrays (SAM) [20]. For this analysis, we used the Multi Experiment Viewer software (MEV, version 4.5.1); the parameters of the analysis included: use of all unique permutations, selection of S0 using the method of Tusher et al. [20] and cutoff $\Delta$-value at false discovery rate zero. Data in figures 1 and 4 are presented as means \pm SEM. Heat maps were produced using the MEV software. 


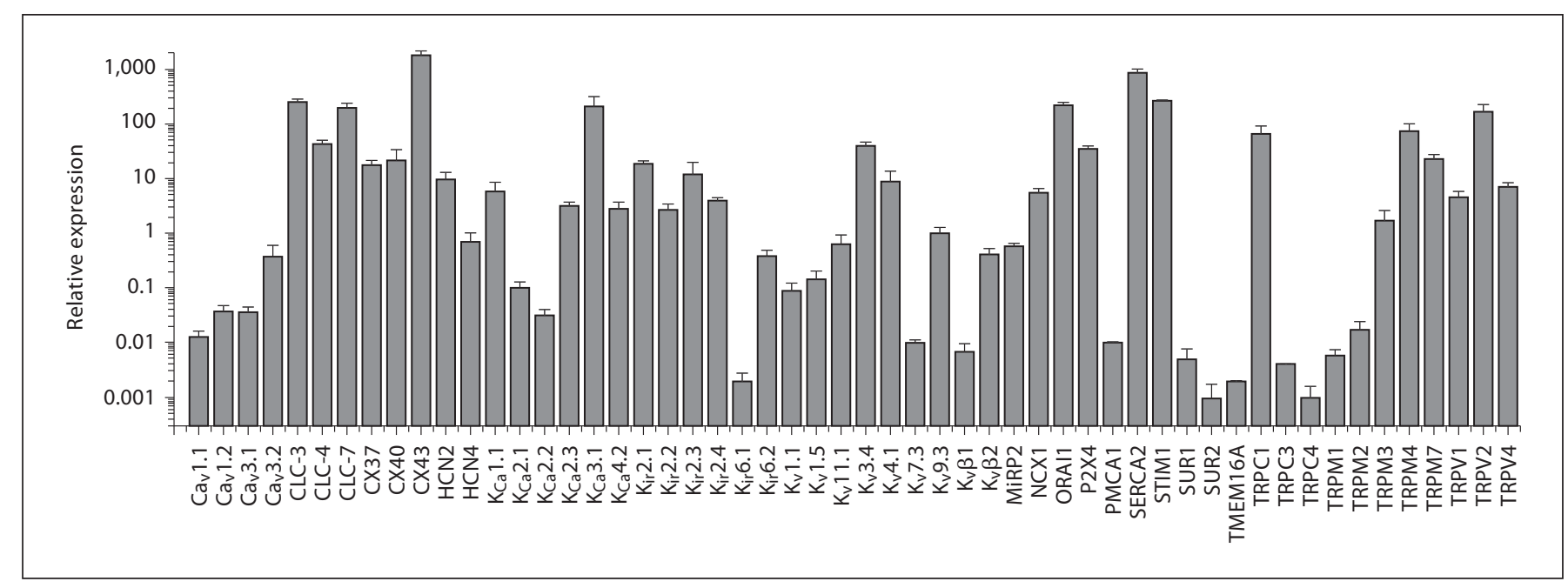

Fig. 1. Expression of ion channel subunits and exchangers in HCAECs under basal conditions. qRT-PCR assays of 6 separate experiments were performed for 54 subunits of ion channels, exchangers and pumps. For each experiment, the expression was calculated relative to that a set of reference genes (see Methods) and depicted on a logarithmic scale. Data are presented as mean \pm SEM.

\section{Analysis of Microarray Data}

Microarray data produced by different investigators are publicly available in Gene Expression Omnibus provided by the $\mathrm{Na}$ tional Center for Biotechnology Information. We examined studies that investigated changes in endothelial gene expression levels due to changes in shear forces. We then looked for changes in ion channel and transporter gene expression. The data used were from the GSE1518 data set record. Raw data were analyzed using the Genespring GX10 software.

\section{Results}

\section{Expression Profiles of Ion Channel Subunits in}

HCAECs

Our first goal was to assess the transcriptional profile of ion channel, exchanger and pump subunits in HCAECs. Microarray data have not been helpful in this regard since ion channels are generally expressed at low levels and are sometimes not readily detected with this method. We therefore used a large-scale qRT-PCR assay [16] and focused on a subset of ion transporter subunits identified from the literature and our past experience. We used a well-characterized commercial primary cell line of HCAECs. Of 55 ion channel, exchanger and pump subunits examined, we found 54 to be expressed at varying degrees in HCAECs under basal conditions (i.e. when cells were grown under static conditions). Their expression levels were calculated relative to 3 reference genes (histone $\mathrm{H} 3$, hydroxymethylbilane synthase, dihydrofolate reductase) and the average expression levels of 6 separate experiments are shown in figure 1 . The qRT-PCRs failed for one of the ion channel subunits $\left(\mathrm{Ca}_{\mathrm{v}} \alpha 2 \delta\right)$, which could be attributed to low expression levels or to ineffective PCR primers. In a few cases, in particular when the channel expression levels were very low, the PCRs did not result in detectable amplification product for some genes. The average expression of the respective genes was calculated from the remaining successful reactions.

\section{$K^{+}$Channel Subunits}

The expression of all 4 members of the $\mathrm{K}_{\mathrm{ir}} 2$ inward rectifying $\mathrm{K}^{+}\left(\mathrm{K}_{\mathrm{ir}}\right)$ channel subfamily was relatively abundant, with $\mathrm{K}_{\mathrm{ir}} 2.1$ and $\mathrm{K}_{\mathrm{ir}} 2.3$ present at higher levels than $\mathrm{K}_{\mathrm{ir}} 2.2$ and $\mathrm{K}_{\mathrm{ir}} 2.4$. The other $\mathrm{K}_{\mathrm{ir}}$ subfamily examined $\left(\mathrm{K}_{\mathrm{ir}} 6\right)$ displayed preferential expression of $\mathrm{K}_{\mathrm{ir}} 6.2$ relative to $\mathrm{K}_{\mathrm{ir}} 6.1$. The $\mathrm{K}_{\mathrm{ir}} 6$ subunit forms a tetrameric assembly with an accessory subunit, the sulfonylurea receptor (SURx). Interestingly, we found SUR1 to be expressed at higher levels relative to SUR2. We also examined expression of $\mathrm{Ca}^{2+}$-activated $\mathrm{K}^{+}\left(\mathrm{K}_{\mathrm{Ca}}\right)$ channel subunits. The large-conductance channel subunit $\left(\mathrm{K}_{\mathrm{Ca}} 1.1\right.$ or slo) was abundantly expressed. $\mathrm{K}_{\mathrm{Ca}} 4.2$ (or Slo2.1) was expressed at equivalent levels. Amongst the small-conductance $\mathrm{Ca}^{2+}$ activated $\mathrm{K}^{+}$channel subunits, $\mathrm{K}_{\mathrm{Ca}} 2.3$ was expressed at higher levels relative to $\mathrm{K}_{\mathrm{Ca}} 2.1$ and $\mathrm{K}_{\mathrm{Ca}} 2.2$. Strong transcriptional expression was observed for the intermediate- 
conductance $\mathrm{Ca}^{2+}$-activated $\mathrm{K}^{+}$channel subunit, $\mathrm{K}_{\mathrm{Ca}} 3.1$ (or $\left.\mathrm{IK}_{\mathrm{Ca}} 1\right)$. Consistent with previous reports [21], we found expression of some of the subunits of the voltagegated $\mathrm{K}^{+}\left(\mathrm{K}_{\mathrm{v}}\right)$ family. Of note is the relatively high expression level of $K_{v} 3.4$ and $K_{v} 4.1$. Amongst the auxiliary subunits of $K_{v}$ channels examined, $K_{v} \beta 2$ and MiRP2 were expressed at equivalent levels and at higher levels relative to $K_{v} \beta 1$.

\section{$\mathrm{Ca}^{2+}$ Channels, Exchangers and Pumps}

ECs are nonexcitable and do not depend on voltage changes for alterations in intracellular $\mathrm{Ca}^{2+}[21]$. Nevertheless, we could detect expression of all 4 of the plasmalemmal voltage-gated $\mathrm{Ca}^{2+}\left(\mathrm{Ca}_{\mathrm{v}}\right)$ channel subunits that we examined. Of these, $\mathrm{Ca}_{\mathrm{v}} 3.2$ was the most abundantly expressed (we did not examine any of the $\mathrm{Ca}^{2+}$ channel subunit auxiliary subunits). Perhaps not surprisingly, higher expression levels were found for subunits involved in alternative pathways for plasmalemmal $\mathrm{Ca}^{2+}$ entry, including ORAI1 and the stromal interaction molecule 1 (STIM1) subunit. Possible mechanisms for plasmalemmal $\mathrm{Ca}^{2+}$ extrusion include the plasma membrane $\mathrm{Ca}^{2+}$ pump (PMCA1, which was expressed at very low levels) and the $\mathrm{Na}^{+} / \mathrm{Ca}^{2+}$ exchanger (NCX1, which was expressed at higher levels). Although our focus was not on intracellular channels, we examined the sarcoplasmic/endoplasmic reticulum $\mathrm{Ca}^{2+}$ pump (SERCA2), which was robustly expressed in these ECs. Extracellular ATP induces $\mathrm{Ca}^{2+}$ influx across the plasma membrane and activates $\mathrm{Ca}^{2+}$ release from intracellular pools in vascular ECs. This process is thought to be mediated by $\mathrm{P} 2 \mathrm{X} 4$ purinergic receptors [22], which we found to be expressed relatively abundantly in HCAECs.

\section{Transient Receptor Potential Channels}

Since the transient receptor potential (TRP) channels are important in endothelial function [21], we systematically examined the expression of 12 members of this channel subunit family. Amongst the TRPCs, TRPC1 was expressed at the highest levels, whereas TRPM4, TRPM7 and TRPM3 were most abundantly expressed in the TRPM subfamily. All 3 members of the TRPV subfamily examined (TRPV1, TRPV2 and TRPV4) were found to be expressed at relatively at high levels.

\section{Other Subunits}

Other subunits examined include those involved in cation and chloride fluxes, and cell-cell communication. We examined two members of the hyperpolarizationactivated cyclic nucleotide-gated ( $\mathrm{HCN}$ ) channels and found both (HCN2 and HCN4) to be expressed in HCAECs. Transcripts of all 3 of the voltage-gated chloride channel family examined (CLC-3, CLC- 4 and CLC7) were highly expressed, whereas TMEM16A (a recently discovered subunit of $\mathrm{Ca}^{2+}$-activated $\mathrm{Cl}^{-}$channels [23]) was expressed at relatively low levels. Finally, amongst the connexins (CX), we found CX43 to be expressed at higher levels relative to $\mathrm{CX} 37$ and CX40.

\section{Transcriptional Remodeling of Ion Channel Subunits}

\section{by Flow Adaptation}

Our next goal was to examine the transcriptional remodeling of ion channel subunits when ECs adapt to increasing shear stress. We employed two levels of flowinduced shear that are commonly used in the literature (5 and $15 \mathrm{dyn} / \mathrm{cm}^{2}$; it should be noted that these values are less than what has been estimated as normal for in vivo shear levels [24]). Cells were grown in an artificial capillary system and subjected to two different flow rates that correspond to two different shear levels ( 5 or $15 \mathrm{dyn} / \mathrm{cm}^{2}$ ) for $24 \mathrm{~h}$. Transcriptional analysis by qRT-PCR was performed as described above and ion channel expression levels were compared to cells grown under static (no flow) conditions. We performed the SAM test (with false discovery rate set to zero) on the data to determine differentially expressed transcripts. With $5 \mathrm{dyn} / \mathrm{cm}^{2}$, we found that the expression of 18 subunits was significantly upregulated and expression of 1 subunit (NCX1) was reduced (fig. 2a). Note that, with the exception of 1 subunit (TRPM7), all of these transcripts were up- or downregulated by more than 2 -fold $\left(\log _{2}\right.$ value higher than 1 or lower than -1). In some cases, e.g. with $\mathrm{K}_{\mathrm{Ca}} 2.3$ and $\mathrm{K}_{\mathrm{Ca}} 2.2$, the upregulation was more than an order of magnitude. The same subset of ion channel transcripts that was upregulated by $5 \mathrm{dyn} / \mathrm{cm}^{2}$ was also upregulated by an increased shear force of $15 \mathrm{dyn} / \mathrm{cm}^{2}$ (table 1). At these higher shear forces, an additional 12 transcripts demonstrated upregulated expression and many were upregulated by 10 times or more (including $\mathrm{K}_{\mathrm{Ca}} 2.3, \mathrm{~K}_{\mathrm{Ca}} 2.2, \mathrm{Cx} 37, \mathrm{~K}_{\mathrm{ir}} 2.3$, $\mathrm{HCN} 2$ and $\mathrm{K}_{\mathrm{Ca}} 3.1$; fig. 2b). Interestingly, NCX1 was not found to be downregulated by the higher shear. It is important to note that ion channel transcriptional remodeling is not a general feature of the $\mathrm{EC}$ response to shear since expression of more than $40 \%$ of the transcripts examined (24/54; table 1) was unaffected by shear. Moreover, the expression levels of the endothelial marker von Willebrand factor (vWF) and of endothelial nitric oxide synthase (eNOS) were examined. These proteins represent a negative and positive control, respectively, of shear stress-induced transcriptional modulation $[25,26]$. In 
Fig. 2. Shear-induced changes in ion channel subunit expression levels. Only the genes that were found to be significantly differentially expressed (by SAM analysis) are shown. HCAECs were exposed to shear force of $5 \mathrm{dyn} / \mathrm{cm}^{2}$ (a) or $15 \mathrm{dyn} / \mathrm{cm}^{2}$ (b). qRT-PCR was performed and expression levels were calculated relative to reference genes. Shown are the ratios (after $\log _{2}$ transformation) of the expression levels under flow compared with the expression levels under static (control) conditions.
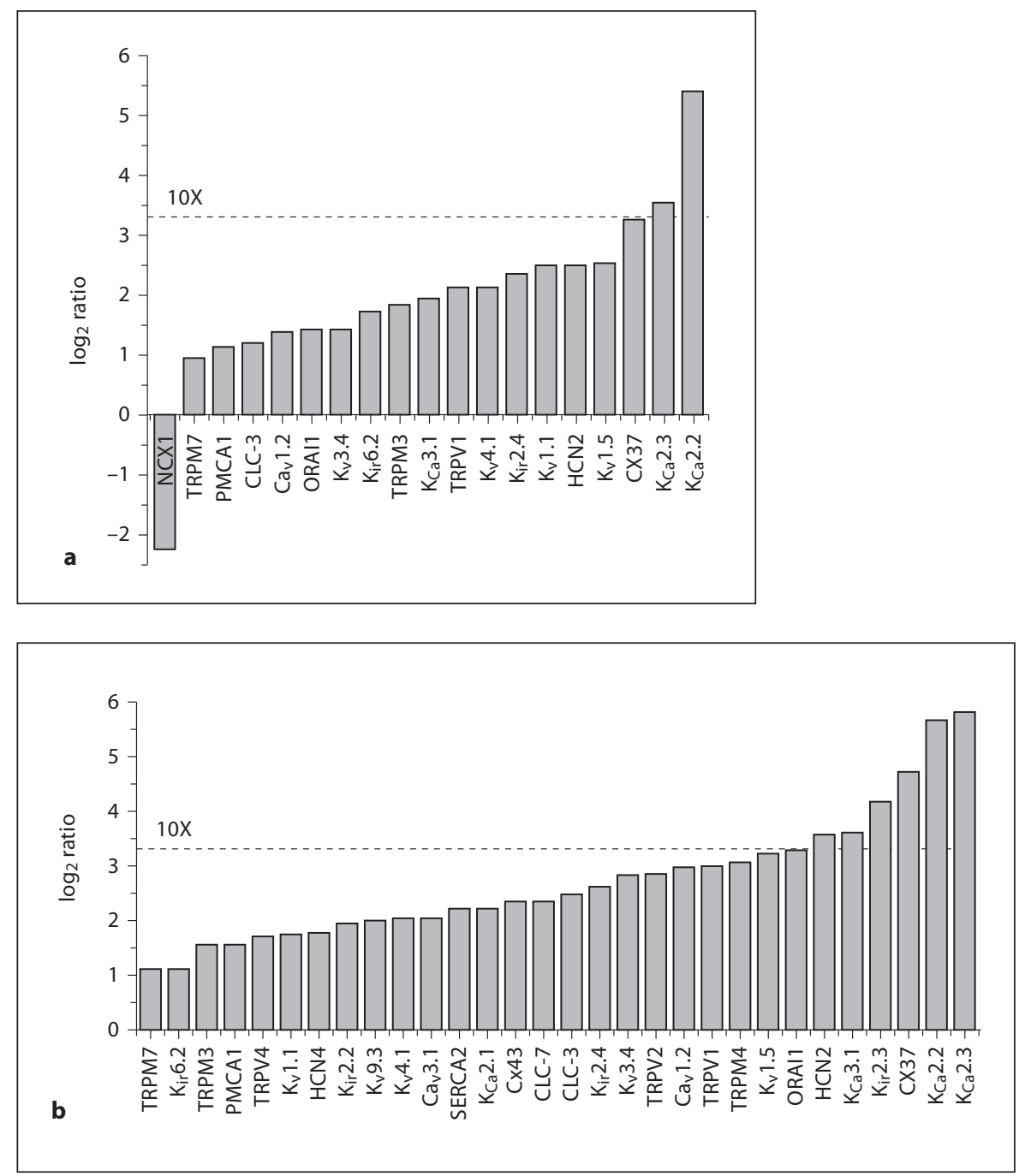

agreement with the literature, vWF was not affected by shear and eNOS was significantly upregulated by both flow levels. The data are summarized as a heat map in figure 3 , which demonstrates not only the heterogeneity of ion channel transcription in HCAECs but also clusters genes with similar expression levels and alterations with shear. Finally, we examined the degree to which the two different levels of shear used in this study influenced the expression profiles of ion translocator subunits. To this end, we plotted the mRNA expression (as a percentage of the set of reference genes) measured at $15 \mathrm{dyn} / \mathrm{cm}^{2}$ as a function of the expression measured at $5 \mathrm{dyn} / \mathrm{cm}^{2}$ (fig. 4). Data were reasonably well described by a linear equation, with a slope of about 2.4. This relationship demonstrates that higher shear levels are associated with increased levels of ion translocator mRNA expression.

\section{Microarray Data Results}

In order to obtain a different perspective of ion channel remodeling by shear forces, we examined publicly available microarray data sets. We focused on studies that compared the gene expression patterns of ECs under static conditions in comparison to different levels of applied shear forces. In one such study (GSE1518), gene expression profiles of human umbilical vein ECs (HUVECs) were examined in response to 4,10 and $25 \mathrm{dyn} / \mathrm{cm}^{2}$ shear levels [27]. Using ANOVA ( $\mathrm{p} \leq 0.01$ ), we obtained 8 ion channel and transporter genes that were differentially regulated between the three conditions (fig. 5). These include 2 lysosomal $\mathrm{H}^{+}$ATPase subunits (ATP6V1A and ATP6V1B2), 2 mitochondrial ATP synthase subunits (ATP5H and ATP5C1), 2 potassium channel subunits (a two-pore channel, KCNK1) and 3 genes encoding pro-

J Vasc Res 2011;48:357-367 
Table 1. Ion channel subunit expression with two flow-induced shear conditions

\begin{tabular}{|c|c|c|c|c|c|}
\hline \multicolumn{2}{|c|}{$\begin{array}{l}\text { Subunits affected } \\
\text { by } 5 \mathrm{dyn} / \mathrm{cm}^{2}\end{array}$} & \multicolumn{2}{|c|}{$\begin{array}{l}\text { Subunits affected } \\
\text { by } 15 \mathrm{dyn} / \mathrm{cm}^{2}\end{array}$} & \multicolumn{2}{|c|}{$\begin{array}{l}\text { Subunits not affected by } \\
\text { flow-induced shear }\end{array}$} \\
\hline $\mathrm{Ca}_{\mathrm{v}} 1.2$ & $\mathrm{~K}_{\mathrm{v}} 1.1$ & $\mathrm{Ca}_{\mathrm{v}} 1.2$ & Kir6.2 & $\mathrm{Ca}_{\mathrm{v}} 1.1$ & $K_{v} \beta 2$ \\
\hline CLC-3 & $\mathrm{K}_{\mathrm{v}} 1.5$ & $\mathrm{Ca}_{\mathrm{v}} 3.1$ & $\mathrm{~K}_{\mathrm{v}} 1.1$ & $\mathrm{Ca}_{\mathrm{v}} 1.3$ & MiRP2 \\
\hline CX37 & $\mathrm{K}_{\mathrm{v}} 3.4$ & CLC-3 & $\mathrm{K}_{\mathrm{v}} 1.5$ & $\mathrm{Ca}_{\mathrm{v}} 3.2$ & $\mathrm{P} 2 \mathrm{X} 4$ \\
\hline $\mathrm{HCN} 2$ & $\mathrm{~K}_{\mathrm{v}} 4.1$ & CLC-7 & $\mathrm{K}_{\mathrm{v}} 3.4$ & CLC-4 & STIM1 \\
\hline $\mathrm{K}_{\mathrm{Ca}} 2.2$ & ORAI1 & CX37 & $\mathrm{K}_{\mathrm{v}} 4.1$ & CX40 & SUR1 \\
\hline $\mathrm{K}_{\mathrm{Ca}} 2.3$ & PMCA1 & CX43 & $\mathrm{K}_{\mathrm{v}} 9.3$ & $\mathrm{~K}_{\mathrm{Ca}} 1.1$ & SUR2 \\
\hline $\mathrm{K}_{\mathrm{Ca}} 3.1$ & TRPM3 & $\mathrm{HCN} 2$ & ORAI1 & $\mathrm{K}_{\mathrm{Ca}} 4.2$ & TMEM16A \\
\hline $\mathrm{K}_{\mathrm{ir}} 2.4$ & TRPM7 & $\mathrm{HCN} 4$ & PMCA1 & $\mathrm{K}_{\mathrm{ir}} 2.1$ & TRPC1 \\
\hline $\mathrm{K}_{\mathrm{ir}} 6.2$ & TRPV1 & $\mathrm{K}_{\mathrm{Ca}} 2.1$ & SERCA2 & $\mathrm{K}_{\mathrm{ir}} 6.1$ & TRPC3 \\
\hline \multirow[t]{6}{*}{ NCX1 } & & $\mathrm{K}_{\mathrm{Ca}} 2.2$ & TRPM3 & $\mathrm{K}_{\mathrm{v}} 11.1$ & TRPC4 \\
\hline & & $\mathrm{K}_{\mathrm{Ca}} 2.3$ & TRPM4 & $\mathrm{K}_{\mathrm{v}} 7.3$ & TRPM1 \\
\hline & & $\mathrm{K}_{\mathrm{Ca}} 3.1$ & TRPM7 & $\mathrm{K}_{\mathrm{v}} \beta 1$ & TRPM2 \\
\hline & & $\mathrm{K}_{\mathrm{ir}} 2.2$ & TRPV1 & & \\
\hline & & $\mathrm{K}_{\mathrm{ir}} 2.3$ & TRPV2 & & \\
\hline & & $\mathrm{K}_{\mathrm{ir}} 2.4$ & TRPV4 & & \\
\hline
\end{tabular}

We performed a SAM test to determine genes regulated by flow: 18 subunits were statistically upregulated and one (NCX1) downregulated by $5 \mathrm{dyn} / \mathrm{cm}^{2}$ shear. A total of 30 subunits were upregulated by $15 \mathrm{dyn} / \mathrm{cm}^{2}$ shear. About $44 \%$ of the subunits (24/54) were not significantly regulated by either of the shear levels.

teins of the solute carrier family; the $\mathrm{Na}^{+}$bicarbonate co-transporter isoform 3 (SLC4A7), the $\mathrm{Na}^{+}-\mathrm{K}^{+}-\mathrm{Cl}^{-}$ co-transporter (SLC12A2) and $\mathrm{K}^{+}-\mathrm{Cl}^{-}$co-transporter 4 (SLC12A7).

\section{Discussion}

The vascular endothelium is sensitive to alterations in shear forces resulting from alterations in blood flow. The ECs respond by alterations in function, which has important consequences for the regulation of vascular function and blood flow. Acute changes in shear forces cause transient adjustments in vessel diameter that are mediated by the release of vasoactive substances and changes in smooth muscle tone. However, changes in shear forces are often chronic, which causes important adaptive alterations in the shape and composition of the blood vessel wall, a process referred to as vascular remodeling. The endothelial events occurring with vascular remodeling may include alterations in the barrier function (cellular permeability), the inflammatory response and alterations in cell proliferation. Genome-wide assays have been performed to identify the expression profiles of endothe- lial genes in response to shear forces and have identified genes with diverse biological functions, including those encoding growth factors, adhesion molecules, coagulation molecules, chemoattractants, proto-oncogenes and vasoactive substances [27-32]. Ion channel subunits can be subject to chronic transcriptional remodeling (e.g. during perinatal development [16]). However, despite a known role for ion channels in endothelial function and sensing alterations in flow-induced shear [21], the effects of shear forces on ion channel transcriptional remodeling are largely unknown. Our study provides insight into the transcriptional remodeling of a large subset of ion channel subunits that are expressed in the coronary vascular endothelium.

\section{Endothelial Electrical Activity and Shear Forces}

ECs are nonexcitable and as such do not generate conducting action potentials in response to electrical or chemical stimuli. Nevertheless, ion channels, pumps and exchangers play a fundamentally important role in the function of ECs [21]. For example, $\mathrm{K}_{\mathrm{ir}}$ channels act to stabilize the membrane potential. We examined only 2 of the $7 \mathrm{~K}_{\mathrm{ir}}$ subfamilies. The $\mathrm{K}_{\mathrm{ir}} 2$ subfamily is thought to play a predominant role in stabilizing the membrane po- 


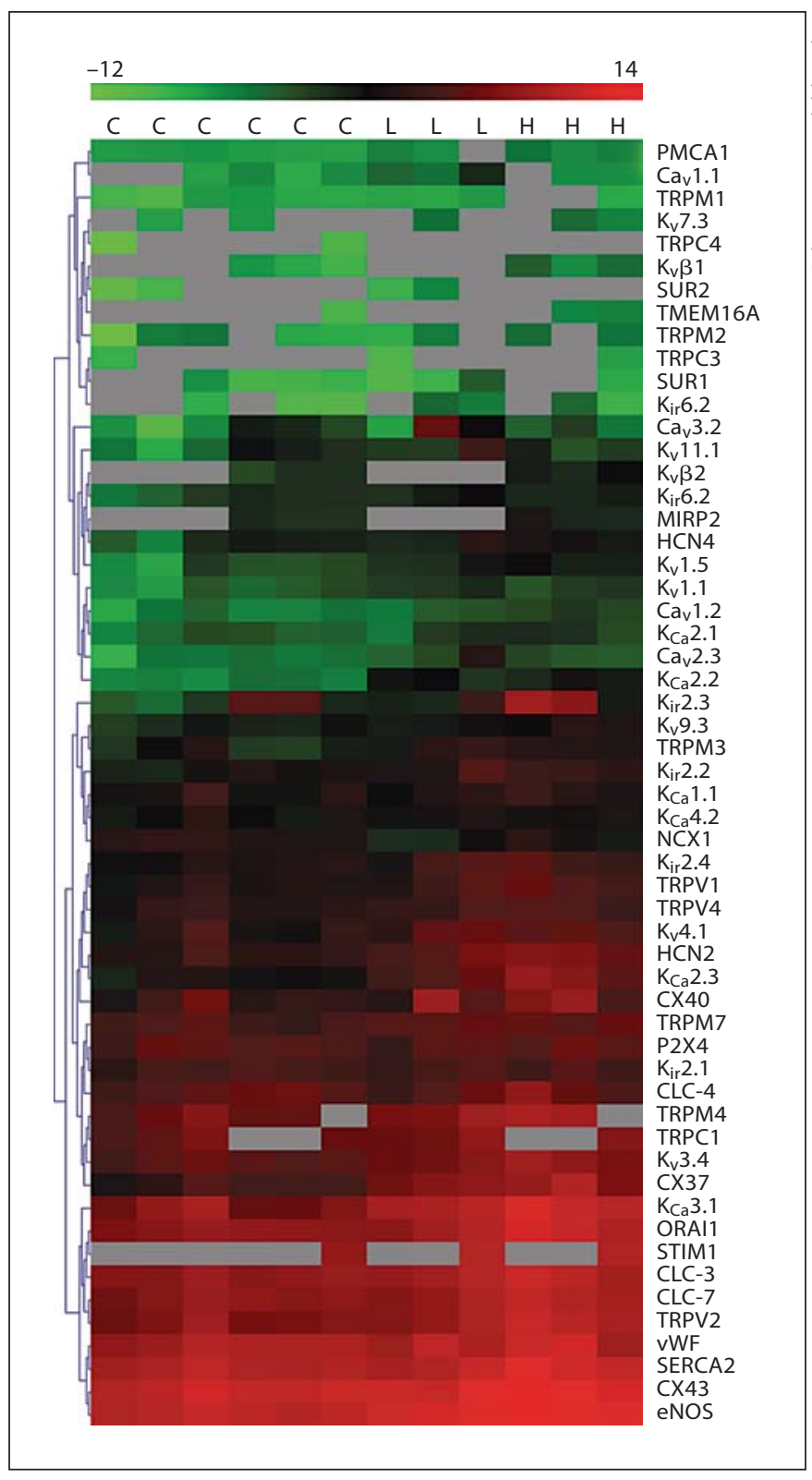

Fig. 3. Heat map of expression data. Data obtained under control conditions and with externally applied shear forces were combined in a heat map. All data are depicted as $\log _{2}$ expression values relative to the same set of reference genes (as described in the text) within the range -12 (green) to 14 (red). Genes are grouped by hierarchical clustering (using the Euclidean distance as a distance measure). Values are shown for 6 control experiments with cells grown under static conditions (C), for 3 experiments where cells were exposed to $5 \mathrm{dyn} / \mathrm{cm}^{2}(\mathrm{~L})$ and 3 experiments where cells were exposed to $15 \mathrm{dyn} / \mathrm{cm}^{2}(\mathrm{H})$ shear for $24 \mathrm{~h}$. The data shown here represents the global dataset (three biological repeats for the two flow conditions, with time-matched static conditions for each of these experiments), which was used to construct figures 1,2 and 4. The gray boxes represent missing data due to failed PCRs, which predictably mostly occurred when gene expression levels were low. Colors refer to the online version only.

Endothelial Flow Adaptation and Ion Channel Remodeling

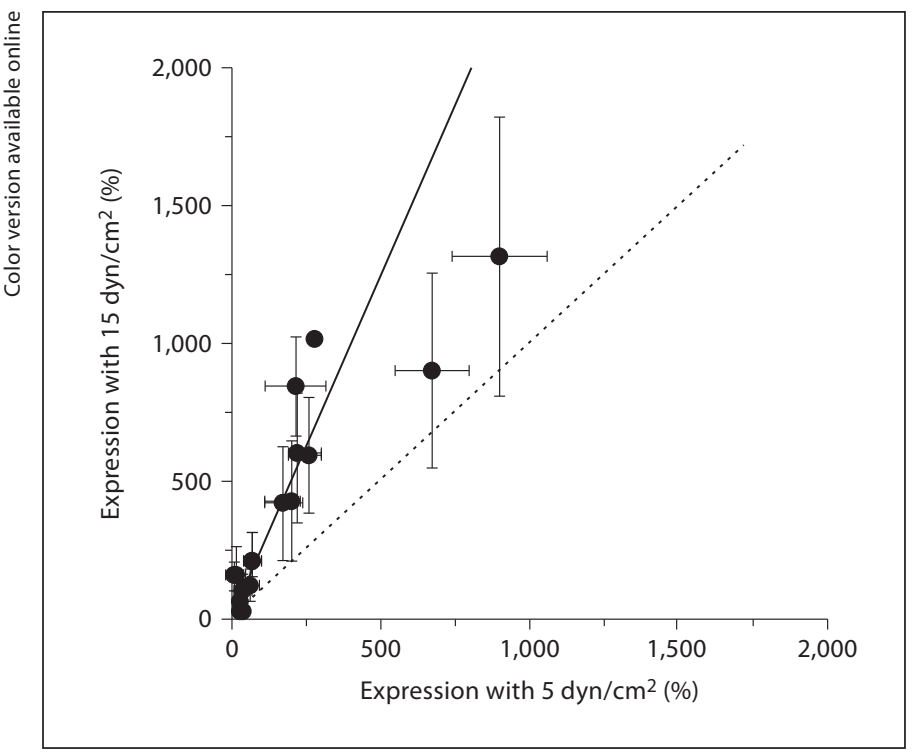

Fig. 4. Relationship between two different applied shear forces on mRNA expression. The mRNA expression levels of 54 ion translocator subunits, relative to the reference genes, were determined at $24 \mathrm{~h}$ applied shear of 5 or $15 \mathrm{dyn} / \mathrm{cm}^{2}$ (expression values relative to reference genes after $\log _{2}$ transformation, same data as in fig. 3). For each subunit, the expression levels at the two shear conditions are plotted as a function of the other. The solid line represents a least-squares fitting of a straight line to the data (slope $=2.4$, intercept forced through zero). For comparison, the dotted line indicates a line with unity slope.

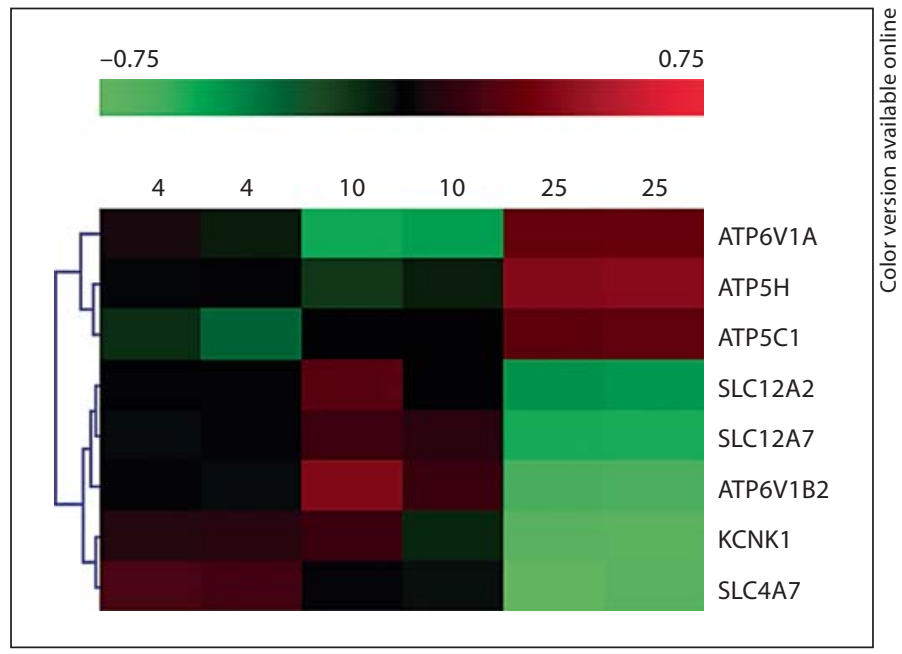

Fig. 5. Microarray analysis of alterations in ion channel and transporter gene expression under different levels of flow. HUVECs were exposed to flow levels of 4,10 or $25 \mathrm{dyn} / \mathrm{cm}^{2}$ and gene expression was examined using microarray analysis [27]. Following $\log _{2}$ transformation, data (ranging from -0.75 to 0.75 ) were subjected to hierarchical clustering and a heat map was generated.

J Vasc Res 2011;48:357-367 
tential [33] and is represented by 4 members $\left(\mathrm{K}_{\mathrm{ir}} 2.1-\right.$ $\left.K_{\mathrm{ir}} 2.4\right)$. We found all 4 of the $\mathrm{K}_{\mathrm{ir}} 2$ members to be abundantly expressed in ECs. Although $\mathrm{K}_{\mathrm{ir}} 2.1$ is the best characterized member of this family in the endothelium, the presence of all members has been previously reported in human aortic ECs [34]. Furthermore, the expression of 3 of these $\left(\mathrm{K}_{\mathrm{ir}} 2.2-2.4\right)$ was upregulated by flow-induced shear, which raises the possibility that shear-adapted ECs may have a more negative membrane potential. We also examined expression levels of another $K_{i r}$ subfamily, namely the $\mathrm{K}_{\mathrm{ir}} 6$ subfamily members $\left(\mathrm{K}_{\mathrm{ir}} 6.1\right.$ and $\left.\mathrm{K}_{\mathrm{ir}} 6.2\right)$, which form an octameric complex with sulfonylurea receptors (SUR1 and SUR2) to form the $\mathrm{K}_{\mathrm{ATP}}$ channel [33]. The latter channel is particularly important in linking alterations in the cellular metabolic status with its electrical activity, but there is also evidence for a role in mechanotransduction [35]. Similar to our previous report [36], we found expression of both $\mathrm{K}_{\mathrm{ir}} 6.1$ and $\mathrm{K}_{\mathrm{ir}} 6.2 \mathrm{in} \mathrm{HCAEC \text {, }}$ with $\mathrm{K}_{\mathrm{ir}} 6.2$ being expressed at higher levels. SUR1 was expressed at higher levels than SUR2, which may partly explain the exquisite sensitivity of ECs to some pharmacological $\mathrm{K}_{\text {АTP }}$ channel openers, such as diazoxide [37]. The shear-induced upregulation of some of these $\mathrm{K}_{\mathrm{ATP}}$ channel subunits observed in our experiments suggests the possibility of an enhanced response of ECs to conditions that impair energy metabolism (e.g. hypoxia) and/ or an increased response to mechanotransduction. Indeed, one of the earliest and most rapid responses of ECs to alterations in hemodynamic forces is the activation of a $\mathrm{K}^{+}$conductance [11], which has recently been identified as a $\mathrm{K}_{\text {ATP }}$ channel current [38]. Thus, upregulation of $\mathrm{K}_{\mathrm{ATP}}$ channel subunits suggests an adaptive response of the EC to further changes in shear forces.

Another important role for $\mathrm{K}^{+}$channels in ECs is to maintain a negative membrane potential upon agonistinduced $\mathrm{Ca}^{2+}$ influx [21]. Although the $\mathrm{K}^{+}$channels discussed above participate in this response, ECs express a specialized class of $\mathrm{Ca}^{2+}$-activated $\mathrm{K}^{+}\left(\mathrm{K}_{\mathrm{Ca}}\right)$ channels that are particularly suited for this role. We examined several members of the $\mathrm{K}_{\mathrm{Ca}}$ family. In keeping with the literature [21], we found strong expression of subunits of members with large conductance $\left(\mathrm{BK}_{\mathrm{Ca}} ; \mathrm{K}_{\mathrm{Ca}} 1.1\right.$ or slo $)$ and intermediate conductance $\left(\mathrm{IK}_{\mathrm{Ca}} ; \mathrm{K}_{\mathrm{Ca}} 3.1\right)$, the latter being strongly upregulated by both shear levels examined. Shear-induced upregulation of $\mathrm{K}_{\mathrm{Ca}} 3.1$ expression has also been noted by others [12]. We could also detect the expression of small-conductance ( $\mathrm{SK}_{\mathrm{Ca}}$ or $\mathrm{K}_{\mathrm{Ca}} 2 . \mathrm{x}$ subfamily) $\mathrm{Ca}^{2+}$ activated $\mathrm{K}^{+}$channel subunits, which were amongst those subunits that were most upregulated by shear forces (fig. 2,3). This suggests that transcriptional plasticity of the small-conductance $\mathrm{Ca}^{2+}$-activated $\mathrm{K}^{+}$channels might have a previously unidentified role in the adaptive response of the EC to chronic changes in blood flow.

Ion channels that are selectively permeable to $\mathrm{Cl}^{-}$ions are ubiquitously expressed, and the EC is no exception [21]. These channels are categorized into several functional groups, which include those activated by voltage, swelling, changes in cytosolic $\mathrm{Ca}^{2+}$, and cyclic nucleotides [39]. The molecular correlates of these functional groups have not been completely resolved. We examined a relatively small subset of $\mathrm{Cl}^{-}$channel subunits and found strong expression of CLC-3, CLC-4 and CLC-7, which are $\mathrm{Cl}^{-} / \mathrm{H}^{+}$exchangers [40]. In contrast, we found low expression levels of TMEM16A, a recently identified subunit of a Ca ${ }^{2+}$-activated $\mathrm{Cl}^{-}$channel. Only CLC-3 and CLC-7 were upregulated significantly by flow-induced shear, suggesting a role for $\mathrm{Cl}^{-}$channels in the adaptive response of an EC to flow changes. Indeed, application of shear stress induces rapid development of a $\mathrm{Cl}^{-}$current in ECs $[41,42]$.

Since ECs are nonexcitable, the expression of voltagegated channels may seem paradoxical. Nevertheless, a variety of voltage-gated channels that are nonselective, or specifically conduct $\mathrm{Na}^{+}, \mathrm{Ca}^{2+}$ or $\mathrm{K}^{+}$ions, are expressed in vascular ECs [21]. Voltage-gated $\mathrm{K}^{+}$channels can have very important roles in nonexcitable cells (for example in controlling $\mathrm{T}$ lymphocyte activation by $\mathrm{K}_{\mathrm{v}} 1.3$ channels [43]). We examined 7 voltage-activated $\mathrm{K}^{+}\left(\mathrm{K}_{\mathrm{v}}\right)$ channel subunits and found relatively abundant expression of several of these, in particular $K_{v} 3.4, K_{v} 4.1$ and $K_{v} 9.3$. It would be of great interest to extend our screen to comprehensively examine the large family of $\mathrm{K}_{\mathrm{V}}$ channel subunits [33]. An important potential role for $\mathrm{K}_{\mathrm{V}}$ channels in nonexcitable cells is to prevent excessive depolarization. As the membrane potential depolarizes into the voltage range where the $\mathrm{K}_{\mathrm{v}}$ channel activates, their opening will minimize further depolarization and therefore clamp the voltage to the activation threshold. In this regard, it is interesting to note that the $\mathrm{K}_{\mathrm{v}}$ channels expressed in ECs have very different activation voltages $\left(\mathrm{K}_{\mathrm{v}} 4\right.$ and $\mathrm{K}_{\mathrm{v}} 3$ channels respectively activate at around -60 and $-10 \mathrm{mV}$ [33]), which raises the possibility that these channels may serve different roles in controlling the EC membrane potential. It is of further interest to note that $\mathrm{K}_{\mathrm{v}} 4.1$ has been described as molecular correlate of the oxygen-sensitive $\mathrm{K}^{+}$ channel in chemoreceptor cells of the rabbit carotid body [44]. Its expression, and upregulation with shear forces, suggests a similar role in the vascular endothelium. In addition to the $K_{v}$ channel subunits, we also found subunits of the hyperpolarization-activated, nonselective 
cation channel (HCN2 and HCN4), which in other tissues are involved in events such as pacemaking activity. These channels are also important in a variety of other cellular responses (e.g. in neurons they participate in motor learning, spatial learning and memory [45]) and their roles in ECs remain to be elucidated. In addition to our qRT-PCR data, the microarray data analysis revealed the electrogenic $\mathrm{Na}^{+}$bicarbonate co-transporter 1 (NBCl; co-transport of $2 \mathrm{HCO}^{3+}$ per $1 \mathrm{Na}^{+}$) to be shear-regulated. Furthermore, the $\mathrm{Na}^{+}-\mathrm{K}^{+}-\mathrm{Cl}^{-}$co-transporter (previously also reported to be regulated by shear in HUVECs by $10 \mathrm{dyn} /$ $\mathrm{cm}^{2}$ of laminar shear [46]) and the $\mathrm{K}^{+}-\mathrm{Cl}^{-}$co-transporter 4 expression levels were modified by shear. The two former subunits are electrically neutral; however, it seems that the transporters that regulate the electrochemical gradient of $\mathrm{Na}^{+}, \mathrm{K}^{+}$and $\mathrm{Cl}^{-}$are, at least to some extent, coregulated under different shear stress conditions.

\section{Endothelial $\mathrm{Ca}^{2+}$ Homeostasis}

One of the first, and perhaps the most important, response of an EC when challenged with agonists or changes in shear forces is an increase in cytosolic $\mathrm{Ca}^{2+}$, which in turn controls events such as activation of proteins (e.g. of eNOS), the release of vasoactive and immunoreactive substances and activation of gene transcription programs. The control of cytosolic $\mathrm{Ca}^{2+}$ is therefore of paramount importance and is orchestrated by ion channels, exchangers and pumps. In addition to the ion channels already discussed above, a rich variety of transport proteins maintain cytosolic $\mathrm{Ca}^{2+}$, both directly and indirectly. Of the limited set of subunits examined, we found significant expression of those that mediate agonist-induced $\mathrm{Ca}^{2+}$ entry (such as TRP channels), those that are involved in store-operated $\mathrm{Ca}^{2+}$ entry (ORAI1 and STIM1), and those that allow $\mathrm{Ca}^{2+}$ entry when the membrane potential is depolarized into their threshold potential $\left(\mathrm{Ca}_{\mathrm{v}}\right.$ channels). Additionally, we found strong expression of a bidirectional $\mathrm{Ca}^{2+}$ transporter, the $\mathrm{Na}^{+}-\mathrm{Ca}^{2+}$ exchanger (NCX1). It is interesting and informative that many of the subunits involved in $\mathrm{Ca}^{2+}$ transport pathways were upregulated by shear forces. This occurred in concert with the upregulation of $\mathrm{Ca}^{2+}$-activated $\mathrm{K}^{+}$channel subunits that coregulate $\mathrm{Ca}^{2+}$ influx (see above), which suggests coordination of the transcriptional mechanisms involved in controlling the levels of proteins implicated in $\mathrm{Ca}^{2+}$ handling.

As with the $\mathrm{K}_{\mathrm{v}}$ channels discussed above, many have questioned the presence or relevance of voltage-activated $\mathrm{Ca}^{2+}$ channels in ECs. Our study provides no additional clues in answering this question. Nonetheless, it is clear that some ECs (e.g. from bovine capillary and adrenal medulla) express both $\mathrm{T}$ - and L-type $\mathrm{Ca}^{2+}$ transient currents that have the ability to mediate $\mathrm{Ca}^{2+}$ entry $[47,48]$. There is evidence that T-type $\mathrm{Ca}^{2+}$ channels participate in $\mathrm{Ca}^{2+}$ influx resulting from shear stress in pulmonary ECs $[14,49]$. The latter result is interesting when considering that the T-type $\mathrm{Ca}^{2+}$ channel subunit $\mathrm{Ca}_{\mathrm{v}} 3.1$ was not only detected but also upregulated by $15 \mathrm{dyn} / \mathrm{cm}^{2}$ shear. Future studies must be directed at unraveling the link between shear and $\mathrm{Ca}_{\mathrm{v}}$ channels.

The TRP channel family is of particular interest given the important role that it has in regulating EC membrane potential and $\mathrm{Ca}^{2+}$ homeostasis [50]. We found several members of the TRP channel families to be expressed in HCAECs. Furthermore, the expression levels of many of these were strongly affected by shear. This finding is in keeping with the literature. For example, TRPV4 $\left(\mathrm{a} \mathrm{Ca}^{2+}\right.$ permeable nonselective cation channel) is activated by various environmental factors, including flow (3-20 dyn/ $\mathrm{cm}^{2}$ ) [51]. We found TRPV4 expression to be increased by shear. TRPM7, a nonselective cation channel with predominant permeability for $\mathrm{Ca}^{2+}$ and $\mathrm{Mg}^{2+}$, rapidly translocates to the plasma membrane in response to changes in flow [52]. Interestingly, TRPM7 expression was also increased by shear in our experiments. Our data point to a potential role for other TRP channels in the adaptive response of an EC to shear.

\section{Channels Involved in Atherosclerosis}

Continuous exposure to a physiologic range of shear stress, especially to unidirectional laminar flow, promotes the establishment of important physiological characteristics of the artery wall, leading to an anti-inflammatory, antithrombotic, anticoagulative and antihypertrophic state, while it is involved in flow-mediated dilation [5]. Alteration of the shear forces alters the biology of the endothelial monolayer and subsequently the susceptibility of vessels to atherosclerosis. Ion channels that are directly implicated in the development of atherosclerosis have not been identified. However, channels that are involved in flow-mediated artery vasodilation, such as TRPV4 [8] and $\mathrm{K}_{\mathrm{Ca}} 3.1$ [53] (which are upregulated in our study by $5 \mathrm{dyn} / \mathrm{cm}^{2}$ or both 5 and $15 \mathrm{dyn} / \mathrm{cm}^{2}$, respectively) or inhibition of EC proliferation, such as TRPM7 [54] (upregulated by both shear levels), could be correlated with atheroprotective effects.

\section{Limitations}

A technical limitation inherent in large-scale qRTPCR is that the analysis often does not correct for differ- 
ences in primer efficiency. Although this is possible (e.g. by producing standard curves for each transcript and primer pair), this procedure is impractical at large scale. Thus, the relative expression of the various subunits (fig. 1) should be interpreted with this limitation in mind. Another obvious limitation of the present study is that we measured transcriptional levels of ion channel subunits, which may not correspond to the functional states of the various ion channels, exchangers and pumps. Translational and post-translational processes may skew this relationship. Nevertheless, our data provide valuable information regarding the profiles and plasticity of groups of ion channels expressed in ECs as the cells adapt to changes in shear forces. Although we examined the expression profiles of a relatively large number (about 60) channel subunits, the reader should note that this represents only a very small subset of the genes identified to date that encode subunits of channels, pumps and exchangers. The total number of transcripts is even larger if one includes events such as alternative splicing and RNA editing. Finally, although we used a relatively well established EC primary line (HCAEC), there may well be important differences when comparing these cells to freshly isolated cells or to ECs in vivo.

\section{Conclusions}

In conclusion, this study provides for the first time a large-scale analysis of ion channel subunit expression in ECs and how this expression is modified by shear stress. The ion channel remodeling observed is substantial and suggests that altered ion channel and transporter expression may significantly contribute to vascular pathology associated with flow-induced alterations. Taken together, results presented here contribute to the understanding of endothelial ion channel regulation and could aid in elucidating their roles in flow-associated diseases.

\section{Acknowledgements}

We are grateful to Dr. Aron B. Fisher and Dr. Shampa Chatterjee (Institute for Environmental Medicine, University of Pennsylvania School of Medicine, Philadelphia, Pa., USA) for kindly providing support and training for the adaptation of ECs to flow. We also thank the NYU Cancer Institute Genomics Facility for access to the high-capacity real-time PCR methodology. The study was supported by a grant from the National Institutes of Health 5R01HL085820-02 and partial support was provided by the 7 th Masonic District.

\section{References}

1 White CR, Frangos JA: The shear stress of it all: the cell membrane and mechanochemical transduction. Philos Trans R Soc Lond B Biol Sci 2007;362:1459-1467.

-2 Fisher AB, Chien S, Barakat AI, Nerem RM: Endothelial cellular response to altered shear stress. Am J Physiol Lung Cell Mol Physiol 2001;281:L529-L533.

- 3 Li YS, Haga JH, Chien S: Molecular basis of the effects of shear stress on vascular endothelial cells. J Biomech 2005;38:1949-1971.

$\checkmark 4$ Chien S: Mechanotransduction and endothelial cell homeostasis: the wisdom of the cell. Am J Physiol Heart Circ Physiol 2007; 292:H1209-H1224.

5 Cunningham KS, Gotlieb AI: The role of shear stress in the pathogenesis of atherosclerosis. Lab Invest 2005;85:9-23.

6 Chiu JJ, Usami S, Chien S: Vascular endothelial responses to altered shear stress: pathologic implications for atherosclerosis. Ann Med 2009;41:19-28.

7 Adams DJ, Hill MA: Potassium channels and membrane potential in the modulation of intracellular calcium in vascular endothelial cells. J Cardiovasc Electrophysiol 2004;15:598-610
8 Folgering JH, Sharif-Naeini R, Dedman A, Patel A, Delmas P, Honore E: Molecular basis of the mammalian pressure-sensitive ion channels: focus on vascular mechanotransduction. Prog Biophys Mol Biol 2008;97:180 195.

-9 Gautam M, Gojova A, Barakat AI: Flow-activated ion channels in vascular endothelium. Cell Biochem Biophys 2006;46:277-284

10 Nakache M, Gaub HE: Hydrodynamic hyperpolarization of endothelial cells. Proc Natl Acad Sci USA 1988;85:1841-1843.

-11 Olesen SP, Clapham DE, Davies PF: Haemodynamic shear stress activates a $\mathrm{K}^{+}$current in vascular endothelial cells. Nature 1988; 331:168-170.

12 Brakemeier S, Kersten A, Eichler I, Grgic I, Zakrzewicz A, Hopp H, Kohler R, Hoyer J: Shear stress-induced up-regulation of the intermediate-conductance $\mathrm{Ca}^{2+}$-activated $\mathrm{K}^{+}$ channel in human endothelium. Cardiovasc Res 2003;60:488-496.

$>13$ Chatterjee S, Al-Mehdi AB, Levitan I, Stevens $T$, Fisher $A B$ : Shear stress increases expression of a $\mathrm{K}_{\mathrm{ATP}}$ channel in rat and bovine pulmonary vascular endothelial cells. Am J Physiol Cell Physiol 2003;285:C959-C967.
14 Wei Z, Manevich Y, Al-Mehdi AB, Chatterjee S, Fisher $\mathrm{AB}: \mathrm{Ca}^{2+}$ flux through voltagegated channels with flow cessation in pulmonary microvascular endothelial cells. Microcirculation 2004;11:517-526.

15 Milovanova T, Manevich Y, Haddad A, Chatterjee S, Moore JS, Fisher AB: Endothelial cell proliferation associated with abrupt reduction in shear stress is dependent on reactive oxygen species. Antioxid Redox Signal 2004;6:245-258.

16 Harrell MD, Harbi S, Hoffman JF, Zavadil J, Coetzee WA: Large-scale analysis of ion channel gene expression in the mouse heart during perinatal development. Physiol Genomics 2007;28:273-283.

17 Rozen S, Skaletsky H: Primer3 on the WWW for general users and for biologist programmers. Methods Mol Biol 2000;132:365-386.

18 Ohl F, Jung M, Xu C, Stephan C, Rabien A, Burkhardt M, Nitsche A, Kristiansen G, Loening SA, Radonic A, Jung K: Gene expression studies in prostate cancer tissue: which reference gene should be selected for normalization? J Mol Med 2005;83:1014-1024. 
19 Andersen CL, Jensen JL, Orntoft TF: Normalization of real-time quantitative reverse transcription-PCR data: a model-based variance estimation approach to identify genes suited for normalization, applied to bladder and colon cancer data sets. Cancer Res 2004; 64:5245-5250.

-20 Tusher VG, Tibshirani R, Chu G: Significance analysis of microarrays applied to the ionizing radiation response. Proc Natl Acad Sci USA 2001;98:5116-5121.

21 Nilius B, Droogmans G: Ion channels and their functional role in vascular endothelium. Physiol Rev 2001;81:1415-1459.

22 Yamamoto K, Korenaga R, Kamiya A, Qi Z, Sokabe M, Ando J: P2X(4) receptors mediate ATP-induced calcium influx in human vascular endothelial cells. Am J Physiol Heart Circ Physiol 2000;279:H285-H292.

23 Galietta LJ: The TMEM16 protein family: a new class of chloride channels? Biophys 2009;97:3047-3053.

-24 Saihara K, Hamasaki S, Okui H, Biro S, Ishida S, Yoshikawa A, Kataoka T, Ninomiya Y, Mizoguchi E, Ichiki T, Otsuji Y, Tei C: Association of coronary shear stress with endothelial function and vascular remodeling in patients with normal or mildly diseased coronary arteries. Coron Artery Dis 2006;17: 401-407.

25 Galbusera M, Zoja C, Donadelli R, Paris S, Morigi M, Benigni A, Figliuzzi M, Remuzzi G, Remuzzi A: Fluid shear stress modulates von Willebrand factor release from human vascular endothelium. Blood 1997;90:15581564.

26 Balligand JL, Feron O, Dessy C: eNOS activation by physical forces: from short-term regulation of contraction to chronic remodeling of cardiovascular tissues. Physiol Rev 2009; 89:481-534

27 Andersson M, Karlsson L, Svensson PA, Ulfhammer E, Ekman M, Jernas M, Carlsson LM, Jern S: Differential global gene expression response patterns of human endothelium exposed to shear stress and intraluminal pressure. J Vasc Res 2005;42:441-452.

-28 Ohura N, Yamamoto K, Ichioka S, Sokabe T, Nakatsuka H, Baba A, Shibata M, Nakatsuka T, Harii K, Wada Y, Kohro T, Kodama T, Ando J: Global analysis of shear stress-responsive genes in vascular endothelial cells. J Atheroscler Thromb 2003;10:304-313.

-29 McCormick SM, Eskin SG, McIntire LV, Teng CL, Lu CM, Russell CG, Chittur KK: DNA microarray reveals changes in gene expression of shear stressed human umbilical vein endothelial cells. Proc Natl Acad Sci USA 2001;98:8955-8960.
30 Chu TJ, Peters DG: Serial analysis of the vascular endothelial transcriptome under static and shear stress conditions. Physiol Genomics 2008;34:185-192.

31 Brooks AR, Lelkes PI, Rubanyi GM: Gene expression profiling of human aortic endothelial cells exposed to disturbed flow and steady laminar flow. Physiol Genomics 2002;9:27-41.

32 Chen BP, Li YS, Zhao Y, Chen KD, Li S, Lao J, Yuan S, Shyy JY, Chien S: DNA microarray analysis of gene expression in endothelial cells in response to 24-h shear stress. Physiol Genomics 2001;7:55-63.

33 Coetzee WA, Amarillo Y, Chiu J, Chow A, Lau D, McCormack T, Moreno H, Nadal MS, Ozaita A, Pountney D, Saganich M, VegaSaenz de ME, Rudy B: Molecular diversity of $\mathrm{K}^{+}$channels. Ann NY AcadSci 1999;868: 233-285.

-34 Fang Y, Schram G, Romanenko VG, Shi C, Conti L, Vandenberg CA, Davies PF, Nattel S, Levitan I: Functional expression of Kir2.x in human aortic endothelial cells: the dominant role of Kir2.2. Am J Physiol Cell Physiol 2005;289:C1134-C1144.

35 Van Wagoner DR: Mechanosensitive gating of atrial ATP-sensitive potassium channels. Circ Res 1993;72:973-983.

- 36 Yoshida H, Feig JE, Morrissey A, Ghiu IA, Artman M, Coetzee WA: K ATP channels of primary human coronary artery endothelial cells consist of a heteromultimeric complex of Kir6.1, Kir6.2, and SUR2B subunits. J Mol Cell Cardiol 2004;37:857-869.

37 Langheinrich U, Daut J: Hyperpolarization of isolated capillaries from guinea-pig heart induced by $\mathrm{K}^{+}$channel openers and glucose deprivation. J Physiol 1997;502 (Pt 2):397408.

-38 Chatterjee S, Levitan I, Wei Z, Fisher AB: KATP channels are an important component of the shear-sensing mechanism in the pulmonary microvasculature. Microcirculation 2006;13:633-644.

- 39 Jentsch TJ, Stein V, Weinreich F, Zdebik AA: Molecular structure and physiological function of chloride channels. Physiol Rev 2002; 82:503-568.

40 Plans V, Rickheit G, Jentsch TJ: Physiological roles of $\mathrm{CLC} \mathrm{Cl}-/ \mathrm{H}^{+}$exchangers in renal proximal tubules. Pflügers Arch 2009;458: 23-37.

41 Barakat AI, Leaver EV, Pappone PA, Davies PF: A flow-activated chloride-selective membrane current in vascular endothelial cells. Circ Res 1999;85:820-828.
42 Gautam M, Shen Y, Thirkill TL, Douglas GC, Barakat AI: Flow-activated chloride channels in vascular endothelium. Shear stress sensitivity, desensitization dynamics, and physiological implications. J Biol Chem 2006;281:36492-36500.

43 Cahalan MD, Chandy KG: The functional network of ion channels in T lymphocytes. Immunol Rev 2009;231:59-87.

44 Sanchez D, Lopez-Lopez JR, Perez-Garcia MT, Sanz-Alfayate G, Obeso A, Ganfornina MD, Gonzalez C: Molecular identification of $\mathrm{K}_{\mathrm{v}} \alpha$ subunits that contribute to the oxygensensitive $\mathrm{K}^{+}$current of chemoreceptor cells of the rabbit carotid body. J Physiol 2002;542: 369-382.

45 Herrmann S, Stieber J, Ludwig A: Pathophysiology of HCN channels. Pflügers Arch 2007;454:517-522.

-46 Topper JN, Wasserman SM, Anderson KR, Cai J, Falb D, Gimbrone MA Jr: Expression of the bumetanide-sensitive $\mathrm{Na}-\mathrm{K}-\mathrm{Cl}$ cotransporter BSC2 is differentially regulated by fluid mechanical and inflammatory cytokine stimuli in vascular endothelium. J Clin Invest 1997:99:2941-2949.

47 Bossu JL, Elhamdani A, Feltz A: Voltage-dependent calcium entry in confluent bovine capillary endothelial cells. FEBS Lett 1992; 299:239-242.

48 Vinet R, Vargas FF: L- and T-type voltagegated $\mathrm{Ca}^{2+}$ currents in adrenal medulla endothelial cells. Am J Physiol 1999;276: H1313-H1322.

49 Fisher AB, Al-Mehdi AB, Manevich Y: Shear stress and endothelial cell activation. Crit Care Med 2002;30:S192-S197.

50 Nilius B, Voets T: Diversity of TRP channel activation. Novartis Found Symp 2004;258: 140-149; discussion 149-159, 263-146.

51 Gao X, Wu L, O’Neil RG: Temperature-modulated diversity of TRPV4 channel gating: activation by physical stresses and phorbol ester derivatives through protein kinase Cdependent and -independent pathways. J Biol Chem 2003;278:27129-27137.

52 Oancea E, Wolfe JT, Clapham DE: Functional TRPM7 channels accumulate at the plasma membrane in response to fluid flow. Circ Res 2006;98:245-253.

53 Tharp DL, Bowles DK: The intermediateconductance $\mathrm{Ca}^{2+}$-activated $\mathrm{K}^{+}$channel $\left(\mathrm{K}_{\mathrm{Ca}} 3.1\right)$ in vascular disease. Cardiovasc Hematol Agents Med Chem 2009;7:1-11.

54 Inoue K, Xiong ZG: Silencing TRPM7 promotes growth/proliferation and nitric oxide production of vascular endothelial cells via the ERK pathway. Cardiovasc Res 2009;83: 547-557. 